\title{
Single Cell-based Screening and Engineering of D-Amino Acid Amidohydrolases using Artificial Amidophenol Substrates and Microbial Biosensors
}

Soo-Jin Yeom ${ }^{1,3, \dagger}$, Kil Koang Kwon ${ }^{1, \dagger}$, Jung-Ung An ${ }^{1, \dagger}$, Sung Hyun Park ${ }^{1,2}$, Jin-Young Lee ${ }^{1}$, Eugene $\mathrm{Rha}^{1}$, Hyewon Lee ${ }^{1}$, Haseong Kim ${ }^{1,2}$, Dae-Hee Lee ${ }^{1,2}$, and Seung-Goo Lee ${ }^{1,2, *}$

${ }^{1}$ Synthetic Biology and Bioengineering Research Center, Korea Research Institute of Bioscience and Biotechnology (KRIBB), Daejeon 34141, Republic of Korea

${ }^{2}$ Department of Biosystems and Bioengineering, KRIBB School of Biotechnology, University of Science and Technology (UST), Daejeon 34113, Republic of Korea

${ }^{3}$ School of Biological Science and Technology, Chonnam National University, Gwangju 61186, Republic of Korea

*Correspondence

Seung-Goo Lee, *E-mail: sglee@kribb.re.kr, Tel: +82-42-860-4373

†These authors contributed equally to this work. 


\section{Supporting Table}

Table S1. The list of primers used in the study

Oligonucleotides $\quad$ Nucleotide sequence $\left(5^{\prime}-3^{\prime}\right)$

\begin{tabular}{|c|c|c|}
\hline \multirow[t]{12}{*}{$\begin{array}{l}\text { For integration of } \\
\text { dmpRGESS }_{\mathrm{E} 135 \mathrm{~K}} \text { into } \\
\text { E. coli } \mathrm{EPI}(\mathrm{DE} 3)\end{array}$} & $\begin{array}{l}\text { bglA_300up } \\
\text { bglA_300dn }\end{array}$ & $\begin{array}{l}\text { GTCAGCAATGACTTTTTTCAGTTCAGTCAG } \\
\text { GGACTATCGCTGGAAGTCGCCGCGCAGGGG }\end{array}$ \\
\hline & pHCE_F1 & ATAGGGGCCTCGCTTACGATCTCTCCTTCACAGA \\
\hline & pHCE_R1 & TTGTACTTGATCGGCATTGATATCTCCTTTTTCC \\
\hline & sfGFP-F1 & GAGAAGGAGATATACATATGAGCAAAGGTGAAGA \\
\hline & sfGFP-R1 & TCCGCCAAAACAGAAGCTTAAGAACCACCTTTTT \\
\hline & dmpR_F1 & GGAAAAAGGAGATATCAATGCCGATCAAGTACAA \\
\hline & pGFP_F1 & TCTGTGAAGGAGAGATCGTAAGCGAGGCCCCTAT \\
\hline & pGFP_R1 & TCTTCACCTTTGCTCATATGTATATCTCCTTCTC \\
\hline & tL3_R1 & TTCATCGACTTAAAGCTGGGCCGCGAATTCACTA \\
\hline & rrnBT_R1 & GGCCGCGGGAATTCGATAAGAGTTTGTAGAAACG \\
\hline & rrnBT_int_F1 & CGTTTCTACAAACTCTTATCGAATTCCCGCGGCC \\
\hline & tL3_int_F1 & TAGTGAATTCGCGGCCCAGCTTTAAGTCGATGAA \\
\hline \multirow{4}{*}{$\begin{array}{l}\text { B. subtilis } \\
\text { KTCC1326 D-amino } \\
\text { acid amidase }\end{array}$} & BS-F & TGCCGCGCGGCAGCCATATGAAGCTGTACATGAG \\
\hline & BS-R & TGGTGGTGGTGCTCGAGTTAGCAGAAACTTGTAC \\
\hline & pET28a(+)BB BB-BS-F & GTACAAGTTTCTGCTAACTCGAGCACCACCACCA \\
\hline & pET28a(+)BB BB-BS-R & CTCATGTACAGCTTCATATGGCTGCCGCGCGGCA \\
\hline \multirow{4}{*}{$\begin{array}{l}\text { B. amyloliquefaciens } \\
\text { KTCC13588 D-amino } \\
\text { acid amidase }\end{array}$} & BA-F & TGGTGCCGCGCGGCAGCCATATGAAACTGTATCTATCTGT \\
\hline & BA-R & TGGTGGTGGTGGTGCTCGAGTTAACAGAATGTTGTTCTCA \\
\hline & pET28a(+)BB-BA-F & TGAGAACAACATTCTGTTAACTCGAGCACCACCACCACCA \\
\hline & pET28a $(+)$ BB BB-BA-R & ACAGATAGATACAGTTTCATATGGCTGCCGCGCGGCACCA \\
\hline \multirow{4}{*}{$\begin{array}{l}\text { B. licheniformis } \\
\text { KTCC1659 D-amino } \\
\text { acid amidase }\end{array}$} & BL-F & TGGTGCCGCGCGGCAGCCATATGAAGCTGTATATGTCTGT \\
\hline & BL-R & TGGTGGTGGTGGTGCTCGAGCTAGGAGAATGTCGTTCTCA \\
\hline & pET28a $(+) B B-B L-F$ & TGAGAACGACATTCTCCTAGCTCGAGCACCACCACCACCA \\
\hline & pET28a $(+)$ BB -BL-R & ACAGACATATACAGCTTCATATGGCTGCCGCGCGGCACCA \\
\hline \multirow{4}{*}{$\begin{array}{l}\text { B. megaterium } \\
\text { KTCC } 3007 \text { D-amino } \\
\text { acid amidase }\end{array}$} & $\mathrm{BM}-\mathrm{F}$ & TGGTGCCGCGCGGCAGCCATATGAAACTATATCTGTCGGT \\
\hline & BM-R & TGGTGGTGGTGGTGCTCGAGCTAACAGAATGTTGTGCGCG \\
\hline & pET28a $(+) B B-B M-F$ & CGCGCACAACATTCTGTTAGCTCGAGCACCACCACCACCA \\
\hline & $\mathrm{pET} 28 \mathrm{a}(+) \mathrm{BB}-\mathrm{BM}-\mathrm{R}$ & ACCGACAGATATAGTTTCATATGGCTGCCGCGCGGCACCA \\
\hline \multirow{4}{*}{$\begin{array}{l}\text { O. anthropi of D- } \\
\text { amino acid amidase }\end{array}$} & OA-F & GGAGAAAGGTACCCCATATGTCTAAATTTGATACATCG \\
\hline & OA-R & TCCTTCCCTCGATGGGCTGCACACGGCGGTATTCC \\
\hline & pET28a $(+)$ BB -OA-F & GGAATACCGCCGTGTGCAGCCCATCGAGGGAAGGA \\
\hline & $\mathrm{pET} 28 \mathrm{a}(+) \mathrm{BB}-\mathrm{OA}-\mathrm{R}$ & CGATGTATCAAATTTAGACATATGGGGTACCTTTCTCC \\
\hline
\end{tabular}


Table S2: Identification of mutations in mBMDaAA hits from DmpR-GESS screening.

Candidates with higher fluorescence intensity in FACS sorting were analyzed to identify mutations. The most frequent mutation, F119, was further studied by introducing sitedirected mutations.

\begin{tabular}{lc}
\hline & Mutations \\
\hline$\# 1$ & T269V \\
$\# 2$ & S61R, K215N \\
$\# 3$ & F119A \\
$\# 4$ & F119A \\
$\# 5$ & F119A \\
$\# 6$ & WT \\
$\# 7$ & L207V \\
$\# 8$ & WT \\
$\# 9$ & F119A \\
\hline
\end{tabular}


Table S3: Comparison of specific activity of F119 variant BMDaaA towards various Damino acid amides. The specific activity was determined as the increase in Unit of $\mu \mathrm{mol} D-$ amino acid produced per $\mathrm{mg}$ protein per min at $55^{\circ} \mathrm{C}$ and $\mathrm{pH} 9.5$ (50 mM CHES buffer) containing 2.5 mM D-alanine amide, D-methionine amide, D-valine amide, D-glutamine amide, D-threonine amide. The enzyme concentration was adjusted in the range of $0.1-25 \mathrm{U} \mathrm{mL}^{-1}$ and the reaction time was $5 \mathrm{~min}$. The reaction was stopped by boiling at $100{ }^{\circ} \mathrm{C}$ for $15 \mathrm{~min}$.

\begin{tabular}{|c|c|c|c|c|c|}
\hline & \multicolumn{5}{|c|}{ Specific activity $\left(\mathrm{U} \mathrm{mg}^{-1}\right)$} \\
\hline & $\begin{array}{l}\text { D-Alanine } \\
\text { amide }\end{array}$ & $\begin{array}{l}\text { D-Glutamine } \\
\text { amide }\end{array}$ & $\begin{array}{l}\text { D-Methionine } \\
\text { amide }\end{array}$ & $\begin{array}{l}\text { D-Valine } \\
\text { amide }\end{array}$ & $\begin{array}{l}\text { D-Threonine } \\
\text { amide }\end{array}$ \\
\hline Wild & $21.07 \pm 0.21$ & $0.07 \pm 0.00$ & $19.72 \pm 0.09$ & $7.36 \pm 0.03$ & $0.01 \pm 0.00$ \\
\hline F119W & $20.15 \pm 0.32$ & $0.06 \pm 0.00$ & $20.68 \pm 0.08$ & $6.47 \pm 0.02$ & $0.02 \pm 0.00$ \\
\hline F119E & $38.95 \pm 0.28$ & $0.65 \pm 0.01$ & $37.85 \pm 0.21$ & $7.87 \pm 0.02$ & $0.02 \pm 0.00$ \\
\hline F119N & $39.15 \pm 0.31$ & $1.11 \pm 0.02$ & $35.73 \pm 0.13$ & $7.56 \pm 0.03$ & $0.01 \pm 0.00$ \\
\hline F119L & $41.41 \pm 0.12$ & $0.05 \pm 0.00$ & $40.78 \pm 0.18$ & $9.05 \pm 0.08$ & $0.06 \pm 0.00$ \\
\hline F119I & $11.21 \pm 0.09$ & $1.26 \pm 0.02$ & $11.30 \pm 0.09$ & $2.22 \pm 0.01$ & $0.01 \pm 0.00$ \\
\hline F119A & $38.61 \pm 0.11$ & $1.79 \pm 0.01$ & $34.73 \pm 0.17$ & $7.94 \pm 0.03$ & $0.08 \pm 0.00$ \\
\hline F119Y & $7.40 \pm 0.06$ & $0.29 \pm 0.03$ & $8.17 \pm 0.06$ & $1.05 \pm 0.01$ & $0.02 \pm 0.00$ \\
\hline F119K & $9.10 \pm 0.04$ & nd & $9.25 \pm 0.06$ & $0.57 \pm 0.02$ & $0.03 \pm 0.00$ \\
\hline F119Q & $5.11 \pm 0.02$ & nd & $6.38 \pm 0.03$ & $0.14 \pm 0.01$ & $0.01 \pm 0.00$ \\
\hline F119V & $38.75 \pm 0.17$ & $0.06 \pm 0.00$ & $35.21 \pm 0.19$ & $7.90 \pm 0.07$ & $0.01 \pm 0.00$ \\
\hline F119R & $5.83 \pm 0.03$ & $0.03 \pm 0.00$ & $6.56 \pm 0.02$ & $0.58 \pm 0.03$ & nd \\
\hline
\end{tabular}

nd: not detected 


\section{Supporting Figure}

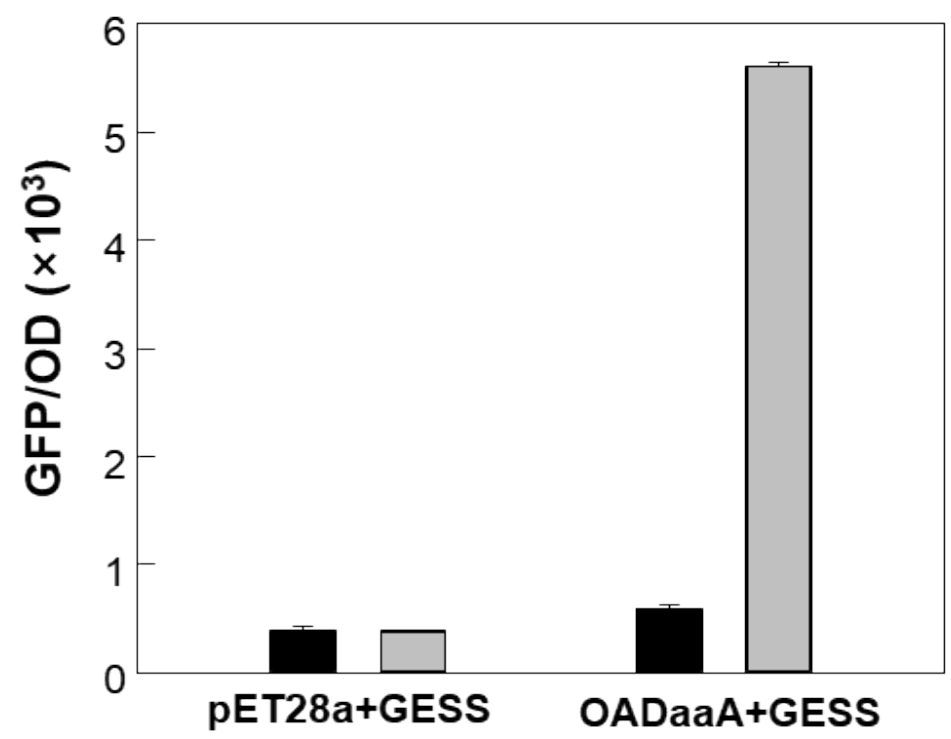

Figure S1. Fluorescence intensity of sensor cells harboring pET-28a plasmid or pET-28a plasmid encoding D-aminopeptidase from Ochrobactrum anthropi (OADaaA). Fluorescence intensity of cells growing M9 media (per liter: $12.8 \mathrm{~g} \mathrm{Na}_{2} \mathrm{HPO}_{4} \cdot 7 \mathrm{H}_{2} \mathrm{O}, 3 \mathrm{~g}$ $\mathrm{KH}_{2} \mathrm{PO}_{4}, 0.5 \mathrm{~g} \mathrm{NaCl}, 1 \mathrm{~g} \mathrm{NH}_{4} \mathrm{Cl}, 2 \mathrm{mM} \mathrm{MgSO}_{4}, 0.1 \mathrm{mM} \mathrm{CaCl}_{2}, 4 \mathrm{~g}$ glucose, and $0.1 \mathrm{~g}$ thiamine) without substrate (black bar) or containing $200 \mu \mathrm{M}$ D-threonine 2-hydroxy phenyl amide (gray bars) at $5 \mathrm{~h}$. Values represent the means \pm SDs of triplicates. 


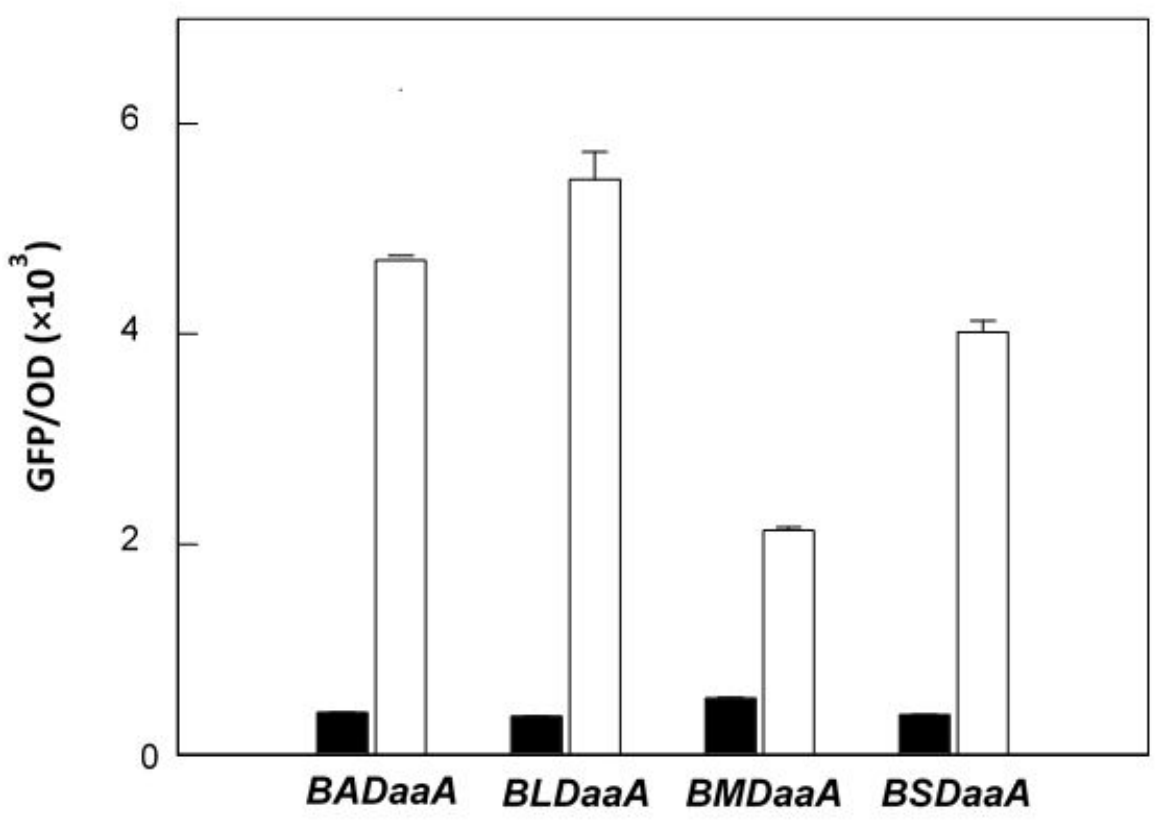

Figure S2. Fluorescence analysis of D-amino acid amidase from Bacillus strains using DmpR-GESS. D-Threonine 2-hydroxy phenyl amide was hydrolyzed by D-amino acid amidase and generated 2-aminophenol that induced intracellular fluorescence signals. Black and empty bars in the graph represented specific fluorescence intensity of cells expressing Damino acid amidase in the presence or absence of $200 \mu \mathrm{M}$ D-threonine 2-hydroxy phenyl amide, respectively. Values represent the means \pm SDs of triplicates. 

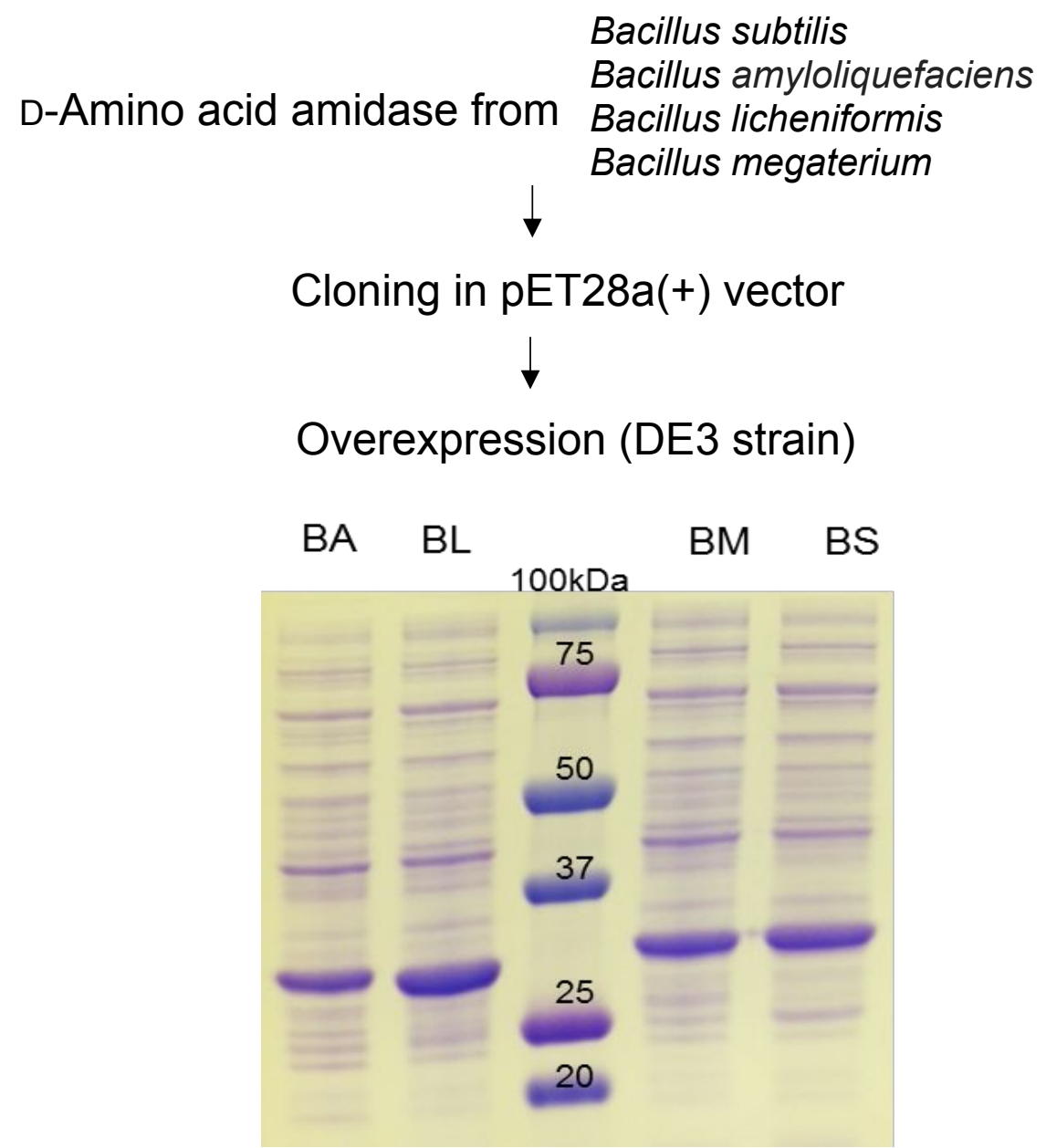

Figure S3. Expression level of D-amino acid amidase from various Bacillus strains. Coding regions of D-aminopeptidase from various Bacillus strains were cloned into the T7 promoter and terminator in vector $\mathrm{pET}-28 \mathrm{a}(+)$ containing the N-terminal $\mathrm{His}_{6}$ tag and expressed in $E$. coli C2566. Cells harboring D-amino acid amidases were grown in LB medium containing 0.1 $\mathrm{mM}$ IPTG at $20^{\circ} \mathrm{C}$ for $18 \mathrm{~h}$. BA, Bacillus amyloliquefaciens; BL, Bacillus licheniformis; BM, Bacillus megatrium; BS, Bacillus subtilis. 

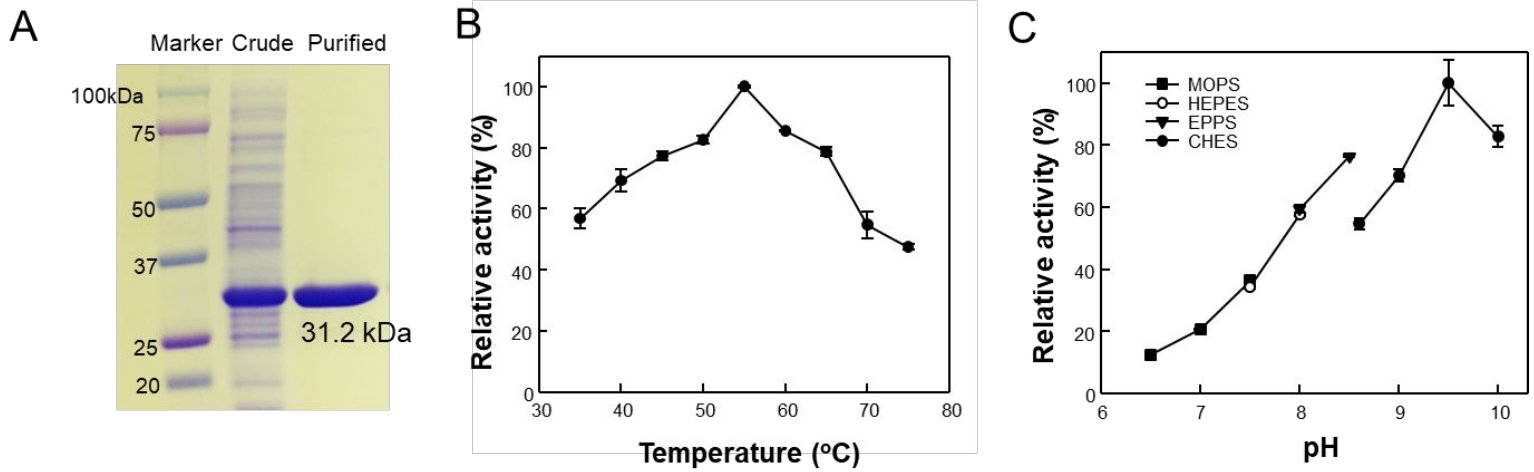

Figure S4. Expression and effects of temperature and pH for the activity of purified Damino acid amidase of $\boldsymbol{B}$. megaterium. (A) SDS-PAGE of D-amino acid amidase expressing in $E$ coli $\mathrm{C} 2566$. Marker, molecular masses are displayed at left in $\mathrm{kDa}$; Crude, cell crude extract expressing recombinant D-amino acid amidase; Purified, purified D-amino acid amidase by His-tag purification. Molecular weight of D-amino acid amidase from B. megaterium was about $31.2 \mathrm{kDa}$. (B) Effect of temperature on D-amino acid amidase. Enzymatic activity was assayed at $35-75^{\circ} \mathrm{C}$ in $50 \mathrm{mM}$ CHES buffer $(\mathrm{pH}$ 9.5) containing $1 \mathrm{mM}$ D-threonine amide for 10 min. (C) Effect of pH on D-amino acid amidase. Enzymatic activity was assayed in $50 \mathrm{mM}$ MOPS (Closed square) buffer (pH 6.5-7.5), 50 mM HEPES (Open circle) buffer (pH 7.5-8.0), $50 \mathrm{mM}$ EPPS (Closed inverted triangle) buffer (pH 8.0-8.5), or CHES (Closed circle) buffer (pH 8.5-10.0) containing $1 \mathrm{mM}$ D-threonine amide at $55^{\circ} \mathrm{C}$ for $10 \mathrm{~min}$. Data are presented as the mean \pm standard error of the mean of three separate experiments. 
A

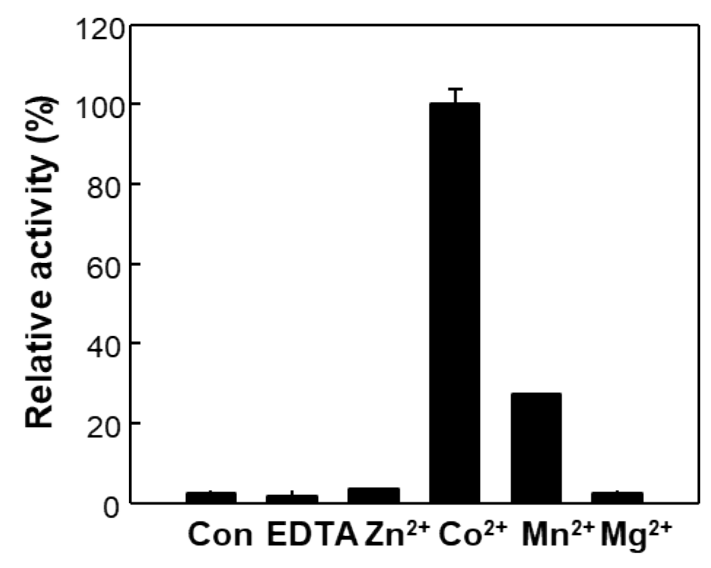

$\mathrm{B}$

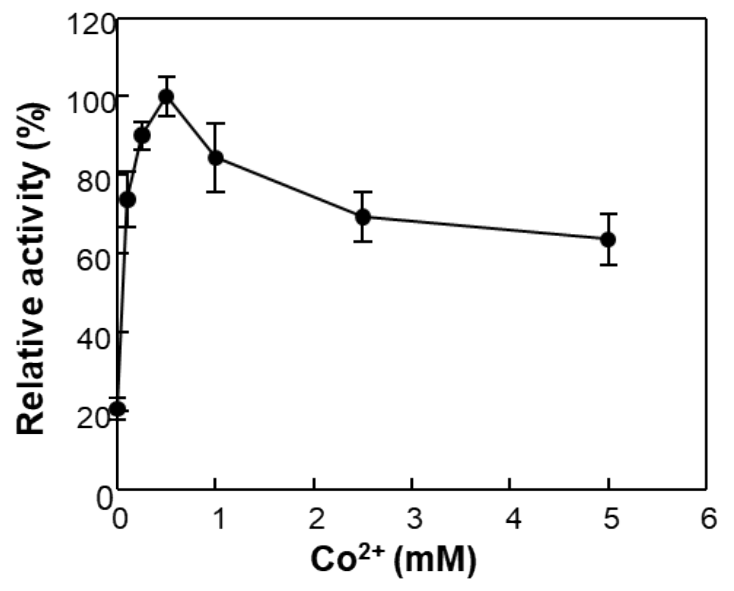

Figure S5. Effects of various metal ion for the activity of D-amino acid amidase from $B$. megaterium. (A) Effect of various $2+$ metal ions on the activity of D-amino acid amidase. The reactions were performed in $50 \mathrm{mM} \mathrm{CHES} \mathrm{buffer}(\mathrm{pH} 9.5)$ containing $1 \mathrm{mM}$ D-threonine amide and metal ions at a concentration of $0.5 \mathrm{mM}$ each at $55^{\circ} \mathrm{C}$ for $5 \mathrm{~min}$. Purified enzyme without EDTA served as a control condition. (B) Effect of $\mathrm{Co}^{2+}$ concentration on the activity of Damino acid amidase. The reactions were performed in $50 \mathrm{mM}$ CHES buffer $(\mathrm{pH} 9.5)$ containing $1 \mathrm{mM}$ D-threonine amide and various concentration of $\mathrm{Co}^{2+}$ ion at $55{ }^{\circ} \mathrm{C}$ for $5 \mathrm{~min}$. Data are presented as the mean \pm standard error of the mean of three separate experiments. 


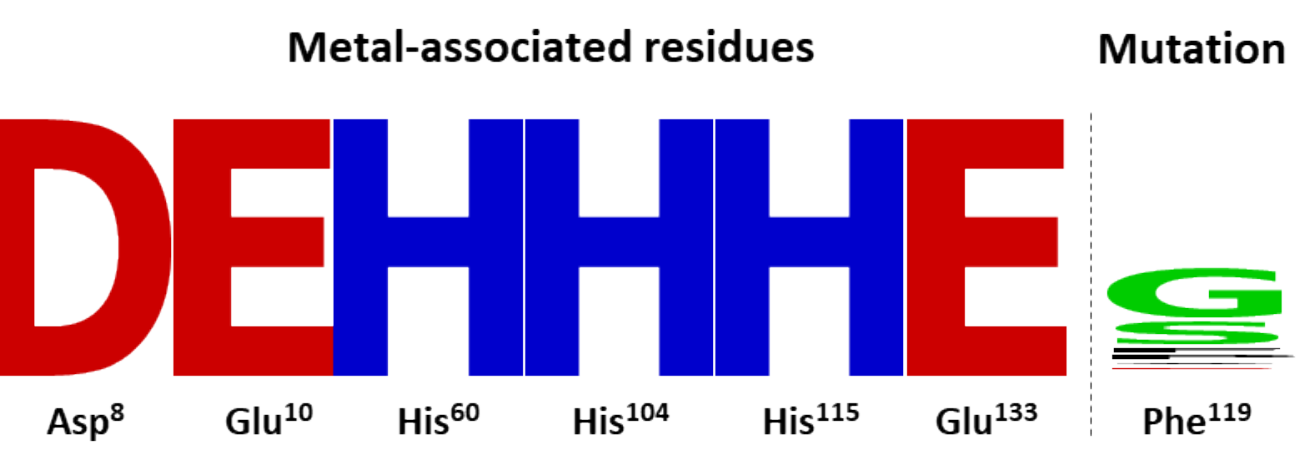

Figure S6. Sequence alignment of metal-associated residues and $P h e^{119}$ in 45 Daminopeptidases. The sequences of 45 D-aminopeptidases from NCBI were aligned to show the conservation of metal-associated residues and mutant residue found in this study. A graph of conserved residues was generated using Weblogo (https://weblogo.berkeley.edu/logo.cgi). 


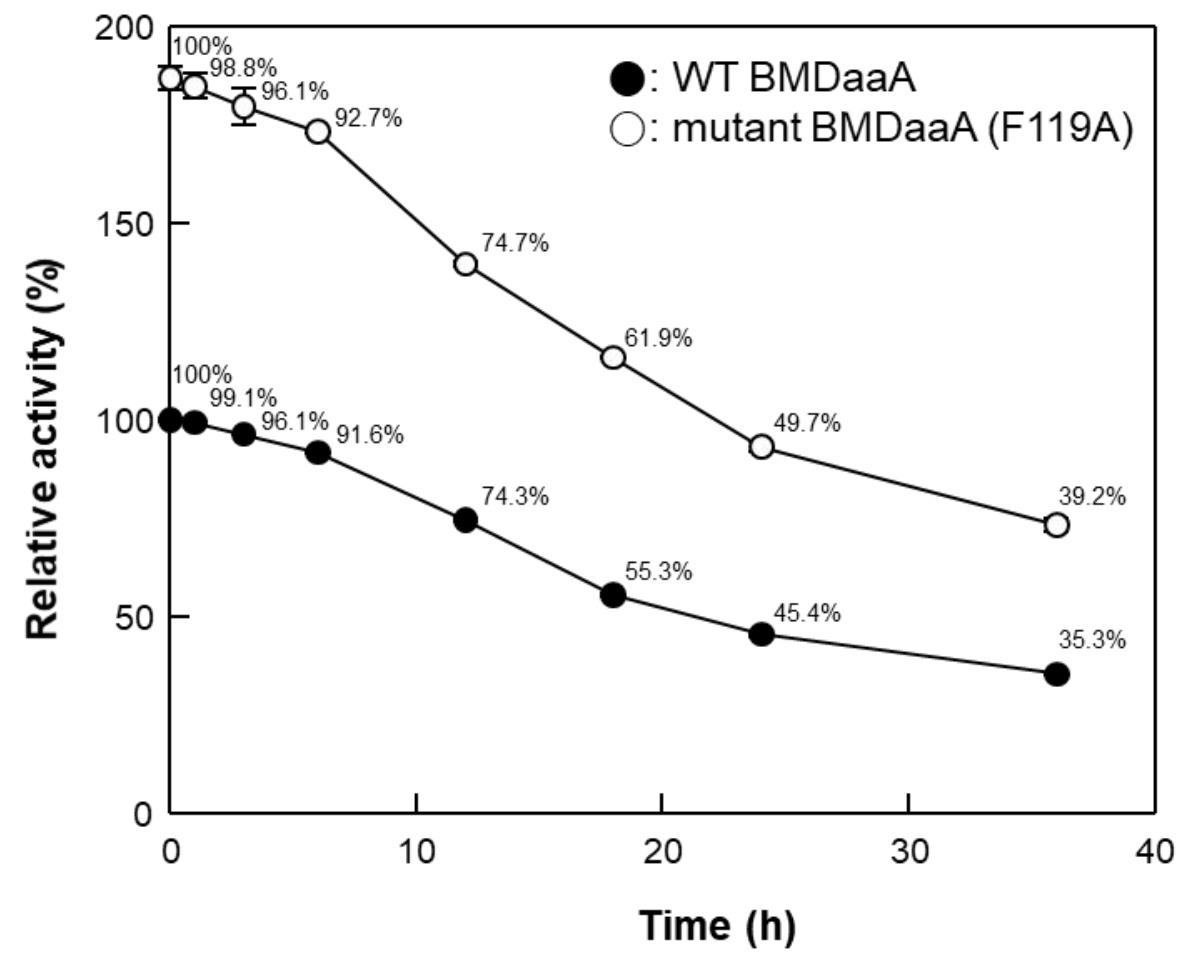

Figure S7. Time-lapse profile of residual activity of wild-type and F119A mutant D-amino acid amidase from $B$. megaterium. The indicated numbers represent the residual activity of each enzyme. Purified enzyme $\left(0.5 \mathrm{mg} \mathrm{mL}^{-1}\right.$ each) were stored in $50 \mathrm{mM}$ CHES buffer ( $\mathrm{pH}$ 9.5) at $55{ }^{\circ} \mathrm{C}$ for up to 36 hours. The reactions were performed in $50 \mathrm{mM}$ CHES buffer ( $\mathrm{pH}$ 9.5) containing $5 \mathrm{mM}$ D-threonine amide, $0.5 \mathrm{mM} \mathrm{Co}^{2+}$ ion at $55{ }^{\circ} \mathrm{C}$ for $10 \mathrm{~min}$. Data are presented as the mean of two separate experiments. 